\title{
A Study of Heart Enzyme Profile in Myocardial Infarction
}

\author{
Muhammad Rafiq Khan*, Khan, $\mathbf{M}^{2}$ and Shah, $\mathbf{A}^{3}$ \\ ${ }^{1,2}$ Department of Environmental Science and Policy, Lahore School of \\ Economics, Lahore, Pakistan \\ ${ }^{3}$ Department of Chemistry, Government College Lahore \\ *drrafiq@1ahoreschool.edu.pk
}

\begin{abstract}
The work reported in this article was carried out to determine the role of cardiac enzymes in myocardial infarction. The cardiac enzyme levels of 30 normal subjects and 30 infarcted subjects were determined and compared by statistical analysis. The peak values of the statistical averages of CPK, AST and LDH were compared. The comparison indicated that the peak levels of cardiac enzymes in infarcted subjects were 1.5 to 6.1 times that of the normal subjects. The results also showed that the correlation between the cardiac enzyme concentration levels and the gravity of myocardial infarction was highly significant. From the results, it may be concluded that whenever there is an occurrence of myocardial infarction, higher levels of cardiac enzymes will be present in the blood of the infracted subjects as compared to that in the blood of normal subjects.
\end{abstract}

Keywords: study, heart, enzymes, profile, myocardial infarction

\section{Introduction}

The heart diseases, are a big challenge for whole humanity in this age. The World Statistics indicates that heart attacks due to ischemic heart disorders are one of the major causes of death, particularly in the Western countries. Out of these several ischemic disorders, myocardial infarction is the major contributor in causing a high death rate. In USA, for example, over $90 \%$ deaths are related to myocardial infarction [1].

In Pakistan, this important subject has not been investigated properly. However, from general diagnostic indications, the myocardial infarction has been recognized as one of the major causes of death particularly in the upper classes and in the intellectuals under tension.

Fixing myocardial infarction as a term of reference, an intensive research is in progress all over the world to determine the factors responsible for it. Methodologies are being developed for its diagnosis and its effective control. Different parameters responsible for its occurrence such as blood cholesterol, blood calcium, etc, are being studied to establish their value as diagnostic tools of myocardial infarction. Some work has also been carried out to correlate heart enzymes with myocardial infarction [2-7] and has been reviewed by Nabel and Braunwald [8].

As different parameters fair differently in different environment, different studies have also been undertaken in Pakistan to investigate the role of 
the parameters highlighted above in the development and diagnosis of ischemic heart diseases in the country [9].

The work reported here was carried out in Collaboration of Coronary Care Unit of Mayo Hospital, Lahore to study the correlation between myocardial infarction and cardiac enzymes.

\section{Subjects and Methods}

\subsection{Patients}

The blood samples of the patients were collected from Coronary Care Unit (CCU) of Mayo Hospital Lahore, Pakistan, soon after being admitted and thus at the start of the diagnosis of myocardial infarction. This introduced some uncertainty about the exact time of the beginning of the disease.

\subsection{Normal Subjects}

The blood samples of the normal subjects were collected from workers of different institutions within and outside Mayo Hospital. The normal subjects included lecturers, doctors, guards, etc, and some housewives.

\subsection{Collection of Samples}

The specimens containing 3 to $5 \mathrm{ml}$ of blood were drained out of the cubital vein of each patient with a disposable syringe within 24 hours of being admitted in the CCU. The blood was allowed to clot. The clotted blood was centrifuged at $3000 \mathrm{rpm}$ and the serum thus separated was analyzed for enzymatic level of creatine phosphokinase (CPK), lactate dehydrogenase (LDH) and aspartate amino transferase (AST).

\subsection{Determination of CPK}

The presence of CPK was determined by Subborow's Method [10]. To each one of the two centrifuged tubes labeled ' Test' and 'Blank' were transferred $1 \mathrm{ml}$ creatine and $1 \mathrm{ml}$ Trisma buffer $\mathrm{pH} 9.0$ followed by the addition of $0.3 \mathrm{ml}$ serum and $1 \mathrm{ml}$ distilled water. The contents of both tubes were mixed and warmed in a water bath at $37^{\circ} \mathrm{C}$ for a few minutes and to each was then added $0.1 \mathrm{ml}$ ATPglutathione solution. The contents were mixed and kept in the water bath again for half an hour. To the tubes was then added $1.6 \mathrm{ml}$ of cold trichloroacetic acid $(20 \% \mathrm{w} / \mathrm{v})$ and the contents of the tubes were allowed to settle for 5 minutes. The tubes were then centrifuged at $1500 \mathrm{rpm}$ for 10 minutes to obtain clear supernatant.

To one $\mathrm{ml}$ supernatant taken in labeled test tubes was added $1 \mathrm{ml}$ acidic molybdic acid solution and $2.5 \mathrm{ml}$ Fisk and Subbarow Solution [11]. The contents were mixed and allowed to stand at room temperature for 30 minutes. The absorbance of blue color developed in the test sample was read against the blank at $660^{\circ} \mathrm{nm}$ in Turner Spectrophotometer Model 350 against the blank. The absorbance values were converted to $\mu \mathrm{g}$ of phosphorus by comparison with a standard curve constructed by developing colors of different intensity with varying concentrations of inorganic phosphorus and plotting their absorbance 
values against concentrations. The creatine kinase activity was calculated from the micrograms of phosphorus as given in the table provided by Sigma Company.

\subsection{Determination of AST}

Aspartate aminotransferase was determined by Reitman Frankel Method [12]. To each one of the two tubes labeled 'Test' and 'Blank' containing $0.3 \mathrm{ml}$ of serum and distilled water respectively, $1.0 \mathrm{ml}$ buffered substrate (12) was transferred. The tubes were placed in a water bath at $37^{\circ} \mathrm{C}$ for 5 minutes. Then $1.0 \mathrm{ml}$ of color reagent was added to each tube. The contents of the tubes were mixed and allowed to stand for 20 minutes. To each tube was then added $10 \mathrm{ml}$ $0.1 \mathrm{~N}-\mathrm{NaOH}$ and their contents were mixed well. The color developed in the test was read against the blank in Turner Spectrophotometer at $505 \mathrm{~nm}$.

AST activity of each sample was determined by comparison with a standard curve constructed by developing colors using varying concentrations of sodium pyruvate and specific substrate [12] and plotting absorbance values against AST activity in International Units.

\subsection{Determination of $\mathrm{LDH}$}

The serum LDH was determined by Latner and Skillen Method [13]. To each one of the two tubes labeled as 'Test' and 'Blank' was transferred $0.1 \mathrm{ml}$ serum and $0.1 \mathrm{ml}$ control reagent respectively. This was followed by the addition of $0.2 \mathrm{ml}$ of buffer in each tube [13]. To each tube was then added $0.1 \mathrm{ml}$ substrate. Then both tubes were incubated in a water bath for three minutes at $37^{\circ} \mathrm{C}$. Next, $0.2 \mathrm{ml}$ of the color reagent was added to each tube and the tubes were reincubated for 5 minutes. Finally, $5 \mathrm{ml}$ of $0.1 \mathrm{~N}-\mathrm{HCl}$ was added to both tubes and the color developed in the test was read against the blank in the spectrophotometer at $500 \mathrm{~nm}$.

The absorbance values were converted into LDH units by comparison with a standard curve prepared by plotting absorbance values obtained after color development with standard LDH concentrations with buffer, substrate and color reagent following the procedure described above for the sample [13].

\section{Statistical Analysis}

For statistical analysis, both normal and infracted cases were divided into three groups on the basis of age and sex. These groups are shown in Tables 1,2 and 3 .

Table 1. Total number of normal cases with their age, sex and percentage distribution in three groups

\begin{tabular}{|l|l|l|l|l|l|}
\hline \multirow{2}{*}{$\begin{array}{l}\text { Age } \\
\text { (Years) }\end{array}$} & \multirow{2}{*}{ Group } & \multicolumn{2}{|c|}{ Male } & \multicolumn{2}{c|}{ Female } \\
\cline { 3 - 6 } & & Number & \%age & Number & \%age \\
\hline $35-45$ & 1 & 6 & 60.00 & 4 & 40.00 \\
$46-55$ & 2 & 5 & 50.00 & 5 & 50.00 \\
$56-65$ & 3 & 7 & 70.00 & 3 & 30.00 \\
Total & & 18 & 60.00 & 12 & 40.00 \\
\hline
\end{tabular}


Table 2. Total number of patients of myocardial infarction with their age, sex and percentage distribution in three groups

\begin{tabular}{|l|l|l|l|l|l|}
\hline \multirow{2}{*}{$\begin{array}{l}\text { Age } \\
\text { (Years) }\end{array}$} & \multirow{2}{*}{ Group } & \multicolumn{2}{|c|}{ Male } & \multicolumn{2}{c|}{ Female } \\
\cline { 3 - 6 } & & Number & \%age & Number & \%age \\
\hline $35-45$ & 1 & 6 & 60.00 & 4 & 40.00 \\
$46-55$ & 2 & 7 & 70.00 & 3 & 30.00 \\
$56-65$ & 3 & 6 & 60.00 & 4 & 40.00 \\
Total & & 19 & 63.33 & 11 & 36.67 \\
\hline
\end{tabular}

Table 3. Age, sex and percentage among 60 normal and infracted patients.

\begin{tabular}{|l|l|l|l|l|}
\hline Group & Male & Female & Total & Percentage \\
\hline Normal & 18 & 12 & 30 & 50.00 \\
Infarcted & 19 & 11 & 30 & 50.00 \\
Total & 37 & 23 & 60 & 30.00 \\
Total & 61.66 & 38.33 & - & 100 \\
\%age & & & & \\
\hline
\end{tabular}

The statistical data was computed by applying Statistical Model of Swin and Scow [14]. The values of Arithmatic Mean, Variance, Standard Deviation, etc, were determined statistically and subsequently applied to calculate $t$ and $p$ values. On the basis of $t$ and $p$ values the coefficient of correlation was calculated to determine the correlation between blood enzyme concentrations and myocardial infarction.

\section{Results and Discussion}

The statistical data of estimated enzymes CPK, AST and LDH in three groups of 30 normal cases are presented in Table 4 and that of infarcted cases are computed in Table 5. The total values of these enzymes in both are computed in Table 6.

Table 4. Statistical data about enzyme levels in 30 normal cases divided in three

groups with Mean \pm S. E

\begin{tabular}{|l|l|l|c|c|c|}
\hline Group & \multirow{2}{*}{ Age } & \multirow{2}{*}{$\begin{array}{l}\text { No. of } \\
\text { Subjects }\end{array}$} & \multicolumn{3}{|c|}{ Mean \pm Standard Deviation } \\
\cline { 4 - 6 } & & & CPK & AST & LDH \\
\cline { 3 - 6 } & & & $\begin{array}{c}\text { Mean } \pm \text { S. } \\
\text { E. }\end{array}$ & Mean \pm S. E & Mean \pm S.E. \\
\hline 1 & $35-45$ & 10 & $4.5 \pm 1.36$ & $18.2 \pm 2.02$ & $110.3 \pm 16.82$ \\
2 & $46-55$ & 10 & $4.8 \pm 2.00$ & $22.4 \pm 1.71$ & $94.1 \pm 6.28$ \\
3 & $56-65$ & 10 & $6.1 \pm 1.46$ & $22.3 \pm 2.09$ & $88.4 \pm 9.76$ \\
\hline
\end{tabular}

Table 5. Statistical data about enzyme levels in 30 myocardial infracted patients divided in three groups with Mean + S. E

\begin{tabular}{|l|l|l|c|c|c|}
\hline Group & \multirow{2}{*}{ Age } & \multirow{2}{*}{$\begin{array}{l}\text { No. of } \\
\text { Subjects }\end{array}$} & \multicolumn{3}{|c|}{ Mean \pm Standard Deviation } \\
\cline { 4 - 6 } & & & CPK & AST & LDH \\
\cline { 4 - 6 } & & & $\begin{array}{c}\text { Mean } \pm \text { S. } \\
\text { E }\end{array}$ & Mean \pm S. E & Mean \pm S.E \\
\hline 1 & $35-45$ & 10 & $23.1 \pm 4.46$ & $43.4 \pm 3.25$ & $168.80 \pm 11.87$ \\
\hline
\end{tabular}




\begin{tabular}{|llllll|}
2 & $46-55$ & 10 & $25.9 \pm 7.58$ & $72.8 \pm 13.23$ & $271.8 \pm 27.89$ \\
3 & $56-65$ & 10 & $37.0 \pm 11.12$ & $50.3 \pm 6.68$ & $210.0 \pm 12.26$ \\
\hline
\end{tabular}

A comparison of peak values of CPK, AST and LDH in Table 4 with the standard normal values fixed by different medical organizations indicates that the cardiac enzyme levels in normal cases are not raised, while Tables 5 indicates significant rise in their values in the three groups of individual enzyme levels in the patients with myocardial infarction. The results computed in Table 4 also indicate that the mean CPK level range in normal controls varied from $(4.5 \pm 1.36)$ to $(6.1 \pm 1.46)$ while those computed in Table 5 show that the mean CPK-levels in the infarcted patients were in the range of $(23.1 \pm 4.46)$ to $(37.0 \pm$ 11.12). This means that the CPK levels are significantly raised after the onset of myocardial infarction. The same holds true for the normal and infracted patients of young and middle age group, but the levels are not proportionately raised in seniors of age group 55 to 65 . The trend of levels is rather disproportionate in case of LDH. This means that CPK may be considered as a single parameter or as a diagnostic tool for myocardial infarction. Many workers agree to this observation. They have suggested that the most reliable single test for the routine diagnosis of myocardial infarction is the CPK activity $[15,16]$. This does not mean that others are not significant. Here, it can be safely suggested that the activity profiles of all three can be used as diagnostic tool for myocardial infarction. This suggestion is also supported by our predecessor's observation that the height to which the cardiac enzymes rise is proportional to the volume of the infracted myocardium [17-18].

The comparison also indicates that the highest rise is in the middle aged groups. It was also observed that 60-70\% myocardial infarction cases belonge to this group, an observation similar to that of many others e.g. Pathy et al [19]. It is also endorsed by WHO criterion, which states that middle age people and above 65 people are more prone to myocardial infarction. In our enquiry, 30$40 \%$ females were observed to have myocardial infarction, which is less than males. Shirani et al reported a case study of myocardial rupture [20]. This is supported by the fact that the yearly enrolment of the female patients in the Coronary Care Unit of Mayo Hospital Lahore was far less than that of the male patients.

Table 6 demonstrates the comparison of peak values of the three cardiac enzymes between 30 normal subjects and 30 infarction cases. This comparison is also highlighted in Figure1-3 (Hectograms).

Table 6. Statistical data about enzyme levels in total 60 normal and myocardial infracted patients divided in three groups with Mean + S. E.

\begin{tabular}{|l|l|l|l|l|}
\hline \multirow{2}{*}{ Group } & \multirow{2}{*}{$\begin{array}{l}\text { No. of } \\
\text { Subjects }\end{array}$} & \multicolumn{3}{|c|}{ Mean \pm Standard Deviation } \\
\cline { 3 - 5 } & & Total CPK & Total AST & Total LDH \\
\cline { 3 - 5 } & & Mean \pm S E. & Mean \pm S. E. & Mean \pm S.E. \\
\hline Normal & 30 & $5.13 \pm 0.9$ & $20.96 \pm 1.14$ & $97.6 \pm 6.80$ \\
Myocardial & 30 & $28.66 \pm 4.69$ & $55.3 \pm 9.33$ & $217.51 \pm$ \\
Infarcted & & & & 13.18 \\
\hline
\end{tabular}




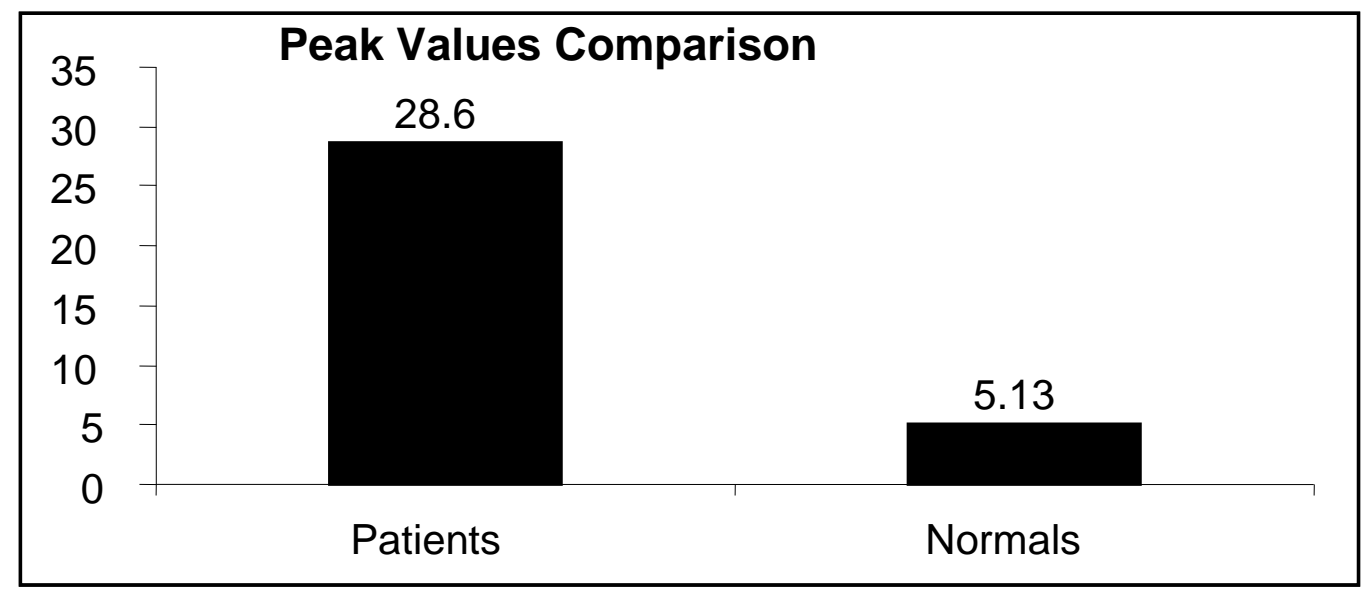

Figure 1. Comparison of peak-values of CPK in normal subjects and patients

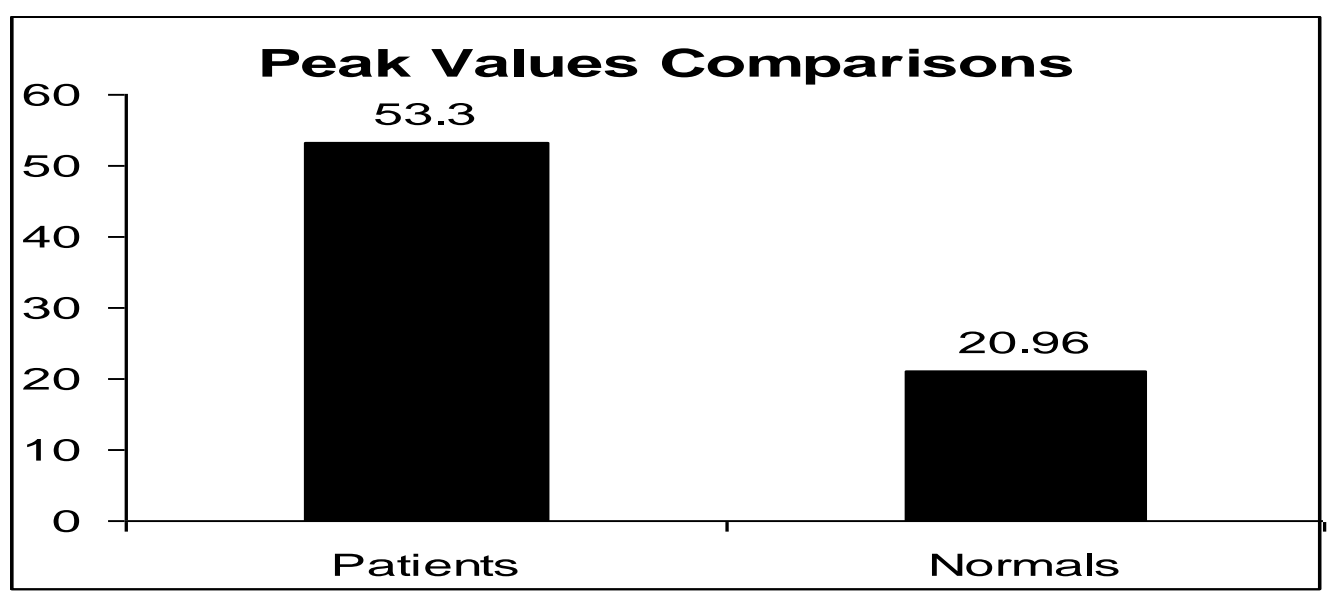

Figure 2. Comparison of peak-values of AST in normal subjects and patients

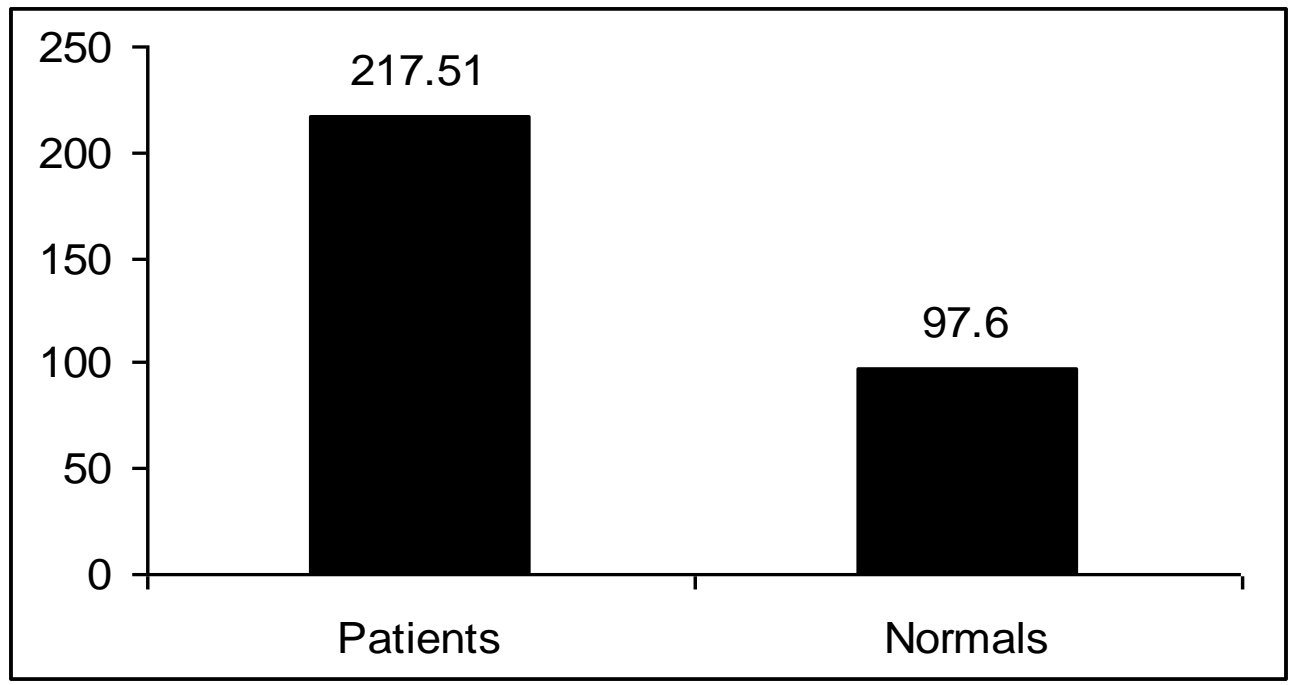

Figure 3. Comparison of peak-values of LDH in normal subjects and patients 
The comparison indicates that the cardiac enzyme levels of patients suffering from myocardial infarction are raised from 1.5 to 6.1 times of the normal levels. The comparative rise of the three enzymes for different age groups is shown in Table 7.

Table 7. Demonstration of the number of times the cardiac enzymes are raised in blood of MI patients as compared to that in normal cases

\begin{tabular}{|l|l|l|l|l|}
\hline Group & Age & CPK & AST & LDH \\
\hline 1 & $35-45$ & 5.1 & 2.4 & 1.5 \\
2 & $46-55$ & 5.4 & 3.3 & 2.9 \\
3 & $56-65$ & 6.1 & 2.3 & 2.4 \\
\hline
\end{tabular}

Apart from the average values reported in the tables, some observations were interestingly indicative in certain contexts. For instance, the highest value of CPK was $73 \mathrm{U} / \mathrm{Ml}$, the AST highest was $160 \mathrm{U} / \mathrm{L}$ and the $\mathrm{LDH}$ value was 400U/L. These values were very high as compared to the average peak values, perhaps indicating very advanced stage of myocardial infarction. In some patients with myocardial infarction, the enzyme levels were high but AST levels were low. In others, LDH was raised, in some CPK and in some all the three were raised. These ups and downs may be due to the site and side of infarction [6] \& [21]. Enzymatic levels of cardiac enzymes also depend on the initial episode of myocardial infarction and date of start of investigation for diagnosis and thus we had to rely on the verbal history narrated by the patients [22]. As the sample collection was random and we did not know the exact time of onset of myocardial infarction, the only base for this episode that could be used as an index was the start of the chest pain and we used it. Although the symptoms are pain with heaviness, tightness, burning in chest, back, left arm, jaw, neck, difficulty in breathing, dizziness, weakness, nausea, vomiting and irregular heartbeat, etc., the chest pain is still considered as the major criterion for diagnosis of myocardial infarction. Of course, we came across few cases without chest pain in the CCU of Mayo Hospital Lahore, From the complete knowledge of the means and standard deviations, the tvalues and p-values of CPK, AST and LDH of 60 normal and infracted patients are reported in Table 8.

Table 8. The t-values and the p-values of CPK, AST and LDH of 60 normal and infracted patients

\begin{tabular}{|l|l|l|l|}
\hline No. & Enzymes & t-Value & p-Value \\
\hline 1 & CPK & 4.43 & $\mathrm{p}<0.001$ \\
2 & AST & 6.24 & $\mathrm{p}<0.001$ \\
3 & LDH & 8.08 & $\mathrm{p}<0.001$ \\
\hline
\end{tabular}

The criteria of judgment with reference to probability $\mathrm{p}$ are as follows:

1. When $\mathrm{p}$ is more than $5 \%$ or it is $>0.05$, the value is regarded as nonsignificant

2. When $\mathrm{p}$ is less than $5 \%$ or it is $<0.05$, the value is regarded as significant' 
3. When $\mathrm{p}$ equal to $1 \%$ or it is $>0.01$, the value is regarded as highly significant.

4. When $\mathrm{p}$ equal to $0.1 \%$ or it is $>0.001$, the value is regarded as very highly significant.

The results presented in Table 8 (Total p-values less than 0.001 for all age groups) correspond to our placement in the last category. Similarly, when the tvalues are 2 or more, the results are highly significant. Here, the t-values are very high. Thus, on the basis of both parameters, there is a highly significant co-relation between the cardiac enzymes and the occurrence of myocardial infarction. This strong conclusion is supported by all other observations.

The activity profile of the cardiac enzymes is an important diagnostic tool for myocardial infarction. In spite of being little heterogeneous, the overall profile sounds highly significant as diagnostic tool. The project may be extended further by relating the enzyme levels with the clinical symptoms of myocardial infarction as here it was observed that majority of the patients did encounter severe chest pain after the onset of the disease, while some patients were also encountered with myocardial infarction without chest pain. The signal in this direction has already been given $[14,20]$.

\section{References}

[1] Robbins WB. Basic Pathology. 3rd ed. Lincoln, UK: Saunder's Company, 1981. (Robbins, SL)

[2] Smith AF. Diagnostic Value of Serum Creatine Phosphokinase. Lancet, 1967; 22(178): Jul 22;2(7508):178-182

[3] Wexler BC. Myocardial and serum lactate changes during isoproterenolinduced infarction. Am Hr J. 1971;81(4): 516-520.

[4] Alderman EL. Evaluation of Enzyme Testing for the Detection of Myoeardial Infarction Following Direct Coronary Surgery. Circulation. 1973;48(1): 135-140.

[5] Witten SAJ. Quantification of Infarct Size by Plasma Enzyme Levels. $\mathrm{Br}$ Hr J. 1975;

Hr. J. 52, 11

[6] Laurse AV, Davids, HA, Hollaar L, et al. and quantification of myocardial injury by means of plasma enzyme and isoenzyme activities after cardiac surgery. Br Hr J. 1979;41(6); 660-667.

[7] K Thygesen, M Hørder, P H Petersen, et al. Limitation of enzymatic models for predicting myocardial infarct size. $\mathrm{Br} \mathrm{Hr} \mathrm{J.} \mathrm{1983;50(1):} \mathrm{70-74.}$

[8] Elizabeth G. Nabel and Eugene Braunwald A Tale of Coronary Artery Disease and Myocardial Infarction. N Engl J Med 2012; 366:54-63. 
[9] Farkhanda K, Fayyaz-ud-Din, MR. Lipid Profiles of the Patients with Coronary Heart Disease and Normal Controls. Pak J Biochem. 1985;XVIII(12): $19-25$.

[10] Tenzer Ml, Gilvarg C. Creatine and Creatine Kinase Measurement. J Biol Chem. 1959;234: 3201-3204.

[11] Fiske CH, Subbarow Y. The Colorimetric Determination of Phosphorus. J Biol Chem. 1925;66: 375-400.

[12] Reitman and Frankel. Am J Clin Path. 1959;58: 56-63.

[13] Latner AL, Skillen AW. Isozyme in Biology and Medicine. New York: Academic Press, 1968.

[14] Khan MM. Functional Abnormalities of Liver and Synalbumin Insulin Antagonist in Diabetes Mellitus. Lahore: Post-Graduate Medical Institute, 1981.

[15] Griffiths PD. Creatine Phosphokinase Chest Pain. Br Hr J. 1966;28: 199203.

[16] Wetner BC. Serum Phosphokinase Activity following Isoproterenal Induced Myocardial infarction. Am Hr J. 1970;79(1): 69-79.

[17] Roe CR, Starmer CF. A Sensitivity Analysis of Enzymatic Estimation of Infarct Size. Circulation. 1975;52: 1-8.

[18] David HA. Extent of Myocardial Damage after Open Heart Surgery Assessed from Serial Plasma Eenzyme. Br Hr J. 1982;47(2): 167-72.

[19] Pathy MS. Myocardial Infarction in the Elderly. Br Hr J. 1967;9(2): 190197.

[20] Shirani J, Berezowski K, Roberts WC: Out-of-hospital sudden death from left ventricular free wall rupture during acute myocardial infarction as the first and only manifestation of atherosclerotic coronary artery disease. Am J Cardiol. 1994, 73:88-92.

[21] Pipberger HV, Arzbaecher RC. Berson AS, et al. Recommendations for standardization of leads and of specifications for instruments in electrocardiography and vectorcardiography: Report of the Committee on Electrocardiography, American Heart Association. Circulation. 1975;52:11-31.

[22] Cobb FR, Irvin RG, Hagerty RC, Roe, CC. Effect of Extension of Infarction on Serial CK Activity. Circulation. 1979;60: 145-154. 